Original Article

\title{
Computerized Tomographic Based Study of Thoracic Spine Morphology in Relevance to Pedicle Screw Fixation in Pakistani Population
}

\author{
Waqas Noor Chughtai, Muhammad Adeel Razzaque, Tanveer Ahmad, Sumera Nighat \\ Rahila Tahir, Bashir Ahmad \\ Bakhtawar Amin Medical College and Hospital, Multan - Pakistan
}

\begin{abstract}
Objective: To study the thoracic spine anatomy for accurate placement of pedicle screws using computerized tomography.

Material and Methods: CT scans of 200 patients were included in our study. T1 to T12 vertebrae morphology was studied for each patient. Following measurements were taken, 1: Transverse pedicle width, $2=$ Depth of anterior cortex along pedicle axis, $3=$ Transverse pedicle angle, $4=$ canal dimensions, $5=$ vertebral body height anterior and posterior, $6=$ mid vertebral body width.

Results: Transverse pedicle width decreased from $\mathrm{T} 1(4.06 \pm 0.50 \mathrm{~mm})$ to $\mathrm{T} 4(3.72 \pm 0.17 \mathrm{~mm})$ and then gradually increases to T12 $(6.08 \pm 0.60 \mathrm{~mm})$. Depth of the anterior vertebral cortex remained constant from T1 to T4 and gradually increases up to T12. Transverse pedicle angle remained constant from T1 to T4 with a maximum at T4 $(23.39 \pm 3.15 \mathrm{~mm})$ and then gradually decreased to T12 $(3.99 \pm 2.16 \mathrm{~mm})$. Anteroposterior (AP) canal dimensions were minimum at T7 $(17.03 \pm 1.01 \mathrm{~mm})$ and maximum at T2 $(21.2 \pm 1.07 \mathrm{~mm})$. Interpedicular (IPD) canal dimensions were minimum at T6 $\left(19.18 \pm \_1.6 \mathrm{~mm}\right)$ and maximum at T3 $(23.18 \pm$ $1.2 \mathrm{~mm})$. Anterior vertebral body height was minimum at T1 $(16.9 \pm 1.34 \mathrm{~mm})$ and maximum at T12 $(27.14 \pm$ $1.34 \mathrm{~mm})$. Posterior vertebral body height was minimum at T1 $(18.8 \pm 1.13 \mathrm{~mm})$ and maximum at T12 $(29.76 \pm$ $1.43 \mathrm{~mm})$.
\end{abstract}

Conclusion: A detailed anatomy of the thoracic spine is essential for surgical planning to decrease postoperative complications.

Keywords: Thoracic spine, Morphology, Pedicle screw fixation (PSF), Interpedicular distance (IPD), Postoperative complications.

Corresponding Author: Waqas Noor Chughtai

Bakhtawar Amin Medical College and Hospital

Multan

Email: drwaqas220@gmail.com
Date of Submission: $10-03-2021$

Date of Revision: 08-04-2021

Date of Online Publishing: 13-06-2021

Date of Print: 30-06-2021

DOI: $10.36552 / p j n s . v 25 i 2.518$ 


\section{INTRODUCTION}

The vertebral column is an important structure of the human body. It provides axial support to the skeleton. It consists of vertebrae, intervertebral discs, spinal cord, and nerves. The thoracic region of the spine is a relatively fixed segment of the spine as compared to cervical and lumbar regions. Thoracic cage provides inherent stability to the thoracic spine. There are 12 thoracic vertebrae and all have facet joints for diarthrodial articulations. The first and last four have specific features with respect to their rib articulation but the rest of the vertebrae are similar. The body of the mid-thoracic vertebrae is heart-shaped and its size is half as compared to cervical and lumbar vertebrae. Each vertebra has two demifacets and these facets form the boundary of the vertebral foramen. The spinal canal is narrowest in the thoracic region which predisposes the spinal cord to severe compression in response to injury. Thoracic pedicle arises superiorly from the dorsal aspect of vertebrae. Pedicle height increases gradually from $\mathrm{T} 1$ to $\mathrm{T} 12$ but the transverse pedicle width does not increase craniocaudally. The vertebral lamina is a flat structure located medial to the superior articular facet. Two laminae join to form the base of a spinous process. The superior articular facet is a shelf-like projection arising from the junction of the pedicle and lamina. The landmark of pedicle screw insertion is 2 to $3 \mathrm{~mm}$ lateral to the midline of superior articular facet. ${ }^{1-4}$

Posterior spine fixation is an important surgical technique for arthrodesis of various spine pathologies like trauma, tumor, infection, deformity. ${ }^{5}$ This rigid fixation can be done by hooks, rods, and wires. Now a days transpedicular screw fixation is the most popular technique for spine surgeries. This has good biomechanical stability. ${ }^{6}$ This allows fusion also at the cervicothoracic and thoracolumbar regions. Pedicle screw fixation has a few complications. Malposition of the screw may result in neurovascular injuries. If there is an anterior cortex breech, it may injure the main vessels ${ }^{7}$. Medial pedicular breech may result in neurological deficit and a breach of $<2 \mathrm{~mm}$ is well tolerated. ${ }^{8}$

Due to the complexity of thoracic spine anatomy and the surgical procedure required, the morphology of this region should be determined preoperatively. Computerized tomography is an important tool to determine the morphology of the spine. By doing preoperative CT scans, we can determine the exact pedicle size, length, and angulation at each level. ${ }^{9}$

As previous data of thoracic spine morphology was available of the white population. An insufficient local data is available in our population. Previous data to determine the morphology of the spine was done by cadaveric techniques or radiologically. CT scan is a gold standard technique for the morphology of the spine. By determining the exact morphology of the spine, we can do a precise diagnosis of disease, biomechanics of the spine, and do proper implant selection. This is due to a growing interest in thoracic spine instrumentation. Therefore, the aim of our study was to determine the detailed morphology of the thoracic spine using a CT scan in our population.

\section{MATERIAL AND METHODS}

\section{Study Design and Settings}

A descriptive study was conducted at the Bakhtawar Amin Hospital, Multan.

\section{Sampling Technique and Sample Size}

Sampling technique was the simple random probability sampling. 200 patients were included in this study.

\section{Inclusion Criteria}

Patients of age between 15 to 60 years with both 
genders were taken in this study. CT scans thorax of these patients were studied in this research. CT scan of thorax was done for other pathologies. These patients do not have any thoracic spine pathologies.

\section{Exclusion Criteria}

Patients having extremes of age. Patients of thoracic spine pathology like trauma, tumor, infection, deformity, and osteoporotic fractures were excluded from our study.

\section{Data Collection}

200 patients' data was studied. Thoracic spine vertebrae $\mathrm{T} 1$ to $\mathrm{T} 12$ were studied in every patient. The study was done for a duration of 2 years from January 2019 to December 2020. Informed consent was taken from every patient and approval from the hospital ethical board was taken. CT scan of thorax was done with a Window length of 300 and window width of 1500 . Slice thickness $4.0 \mathrm{~mm}$. All measurements were done by a single observer to prevent interobserver discrepancy. The bone window was used to do measurements of the spine.

\section{Radiographic Measurements}

Axial images of the spine were selected for measurements of pedicle morphology, canal size. The level of cut was selected where right and left pedicles appear maximum in dimensions. Midsagittal images were taken for the calculation of vertebral body dimensions. The software Radiant DICOM Viewer 2020.1 (64 bit) was used to measure the dimensions of vertebrae. In the measurement and tools section of the software, the length, width, and angle tools were used. The scale which is present in software was used to draw lines along the relevant dimension to get measurements in millimeters and degree of angulation.

The following measurements were done of the vertebrae on these regions:

a. Transverse pedicle width: It is the width of the pedicle in the transverse plane. The width of the pedicle was measured from the outer cortex to the outer cortex of the pedicle.

b. Depth of anterior vertebral cortex along pedicle axis: This is the length of the pedicle which is taken from the posterior cortex of lamina posteriorly then along the pedicle longitudinal axis to the anterior cortex of the vertebral body.

c. Transverse pedicle angle: This is the transverse pedicle angle made by two lines. One-line is drawn along the pedicle longitudinal axis and another line is along with the AP midline axis.

d. Canal dimensions: Canal dimensions were measured in AP (Anteroposterior) and IPD (Interpedicular) planes.

e. Vertebral body height: Both anterior and posterior vertebral body height were measured from superior to inferior endplates.

f. Vertebral body width: vertebral body width was measured at the middle of the vertebral body.

\section{Data Analysis}

Mean, standard deviation, minimum and maximum measurements were calculated in SPSS version 25. Demographic analysis was done for age and gender.

\section{RESULTS}

\section{Age \& Gender Distribution}

There were $43.5 \%$ male and $56.5 \%$ female in study.

\section{Age Distribution}

Mean age was $38.09 \pm 8.94$ years. Age range was 20 to 60 years.

There was no significant difference in data of 
right and left pedicles, so both were analyzed together.

\section{Transverse Pedicle Width}

Transverse pedicle width was minimum at T4 (3.72 $\pm 0.17 \mathrm{~mm})$. Maximum was observed at T12 $(6.08 \pm 0.60 \mathrm{~mm})$. At T1 level the width was (4.06 $\pm 0.50 \mathrm{~mm})$. The pedicle width gradually decreased from T1 to T4 and increased till T12. At T1 and T5 levels, $92 \%$ of pedicles were smaller than $5 \mathrm{~mm}$ at $\mathrm{T} 1$ and $84 \%$ of pedicles were smaller than $5 \mathrm{~mm}$ at T5. So these pedicles cannot accommodate $4 \mathrm{~mm}$ screw having $1 \mathrm{~mm}$ clearance. At T12 level, 94\% of pedicles were smaller than $7 \mathrm{~mm}$, so these cannot accommodate $6 \mathrm{~mm}$ screw having $1 \mathrm{~mm}$ clearance (Figure 1).

\section{Depth of Anterior Cortex}

Depth of anterior vertebral cortex remained constant from T1 (29.42 $\pm 2.780 \mathrm{~mm}$ to T4 (28.99 $\pm 2.66 \mathrm{~mm}$ ) and gradually increases up to T12 (41.53 $\pm 2.07 \mathrm{~mm}$ ). T1 to T4 vertebrae can accommodate a screw length of $25 \mathrm{~mm}$. T5 and T6 levels up to $30 \mathrm{~mm}$. T7 to T12 levels can accommodate a screw of $35-40 \mathrm{~mm}$ (Table 1).

\section{Transverse Pedicle Angle}

Transverse pedicle angle remained constant from $\mathrm{T} 1$ to T4 with a maximum at T4 $(23.39 \pm 3.15 \mathrm{~mm})$ and then gradually decreased to T12 (3.99 \pm 2.16 $\mathrm{mm}$ ) (Table 1).

\section{Canal Dimensions}

Anterior (AP) canal dimensions remain stable

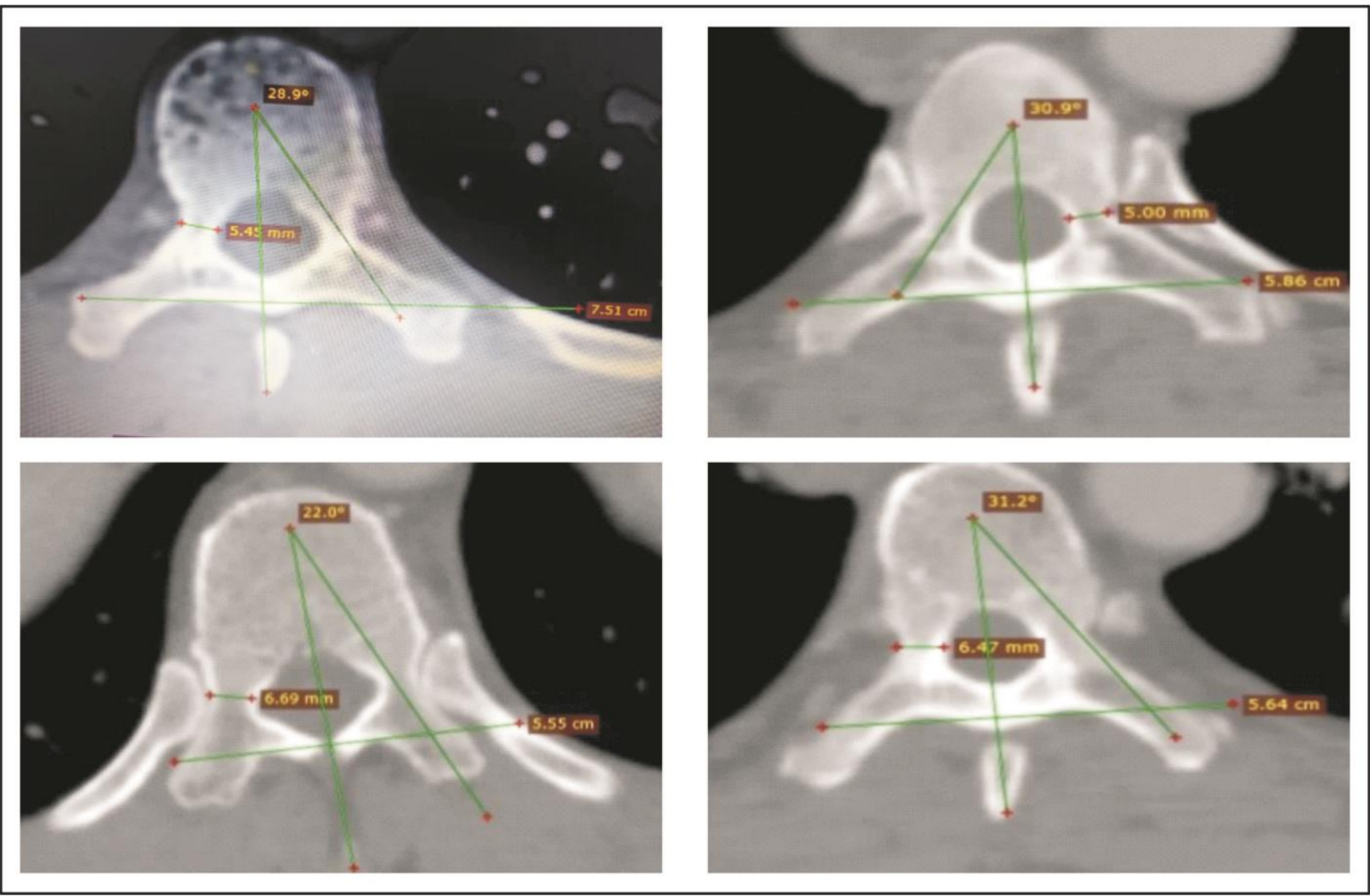

Figure 1: CT Scan Measurements of Thoracic Spine. 
between $\mathrm{T} 1$ and $\mathrm{T} 12$ with a minimum at T7 (17.03 $\pm 1.01 \mathrm{~mm})$ and a maximum at T2 $(21.2 \pm 1.07$ $\mathrm{mm}$ ). Interpedicular (IPD) canal dimensions were minimum at $\mathrm{T} 6(19.18 \pm 1.6 \mathrm{~mm})$ and maximum at T3 $(23.18 \pm 1.2 \mathrm{~mm})$ (Table 1$)$.

\section{Vertebral Body Height Anterior and Posterior}

Vertebral body height anterior and posterior both gradually increased from T1 down to T12. At all levels, posterior vertebral body height is greater than anterior body height. Anterior vertebral body height was minimum at T1 level having a mean of $16.9 \pm 1.34 \mathrm{~mm}$ and maximum at $\mathrm{T} 12$ vertebral level having a mean of $27.14 \pm 1.34 \mathrm{~mm}$. Posterior vertebral body height was minimum at T1 level having a mean of $18.8 \pm 1.13 \mathrm{~mm}$ and maximum at T12 level with a mean of $29.76 \pm$ $1.43 \mathrm{~mm}$ (Table 1).

\section{Mid-body Vertebral Width}

Vertebral body width increased from T1 to T12 level. It was minimum at $\mathrm{T} 2$ level with a mean of $32.1 \pm 2.41 \mathrm{~mm}$ and maximum at T12 level with a mean of $44.27 \pm 3.21 \mathrm{~mm}$.

Table 1: Measurements of the Spine on CT.

\begin{tabular}{|c|c|c|c|c|c|c|c|c|}
\hline Level & $\begin{array}{l}\text { Transverse } \\
\text { Pedicle } \\
\text { Width } \mathbf{m m}\end{array}$ & $\begin{array}{l}\text { Pedicle } \\
\text { Angle }^{0}\end{array}$ & $\begin{array}{l}\text { Depth of } \\
\text { Anterior } \\
\text { Cortex mm }\end{array}$ & $\begin{array}{l}\text { Canal } \\
\text { Dimension } \\
\text { AP mm }\end{array}$ & $\begin{array}{l}\text { Canal } \\
\text { Dimension } \\
\text { IPD } \\
\text { mm }\end{array}$ & $\begin{array}{l}\text { Vertebral } \\
\text { Body Height } \\
\text { Anterior } \\
\text { mm }\end{array}$ & $\begin{array}{l}\text { Vertebral } \\
\text { Body Height } \\
\text { Posterior } \\
\text { mm }\end{array}$ & $\begin{array}{l}\text { Mid Vertebral } \\
\text { Body Width } \\
\text { mm }\end{array}$ \\
\hline T1 & $4.06 \pm 0.50$ & $23.3 \pm 3.1$ & $29.42 \pm 2.78$ & $18.01 \pm 1.2$ & $22.4 \pm 1.4$ & $16.9 \pm 1.34$ & $18.8 \pm 1.13$ & $32.6 \pm 1.11$ \\
\hline T2 & $3.75 \pm 0.16$ & $23.2 \pm 3.22$ & $29.11 \pm 2.76$ & $21.2 \pm 1.07$ & $21.22 \pm 1.3$ & $17.98 \pm 1.3$ & $19.81 \pm 2.01$ & $32.1 \pm 2.41$ \\
\hline T3 & $3.75 \pm 0.15$ & $23.03 \pm 3.29$ & $29.12 \pm 2.77$ & $20.1 \pm 1.1$ & $23.18 \pm 1.2$ & $20.13 \pm 1.49$ & $20.1 \pm 1.31$ & $32.67 \pm 2.14$ \\
\hline $\mathrm{T} 4$ & $3.72 \pm 0.17$ & $23.39 \pm 3.15$ & $28.99 \pm 2.66$ & $19.01 \pm 1.20$ & $21.22 \pm 1.6$ & $20.98 \pm 1.51$ & $21.2 \pm 1.13$ & $33.23 \pm 2.34$ \\
\hline T5 & $4.54 \pm 0.27$ & $13.31 \pm 3.16$ & $37.63 \pm 1.60$ & $19.6 \pm \_1.16$ & $20.9 \pm 1.9$ & $21.7 \pm 1.47$ & $22.35 \pm 1.32$ & $35.12 \pm 2.17$ \\
\hline T6 & $4.56 \pm 0.28$ & $12.83 \pm 3.24$ & $34.54 \pm 4.49$ & $18.5 \pm 1.17$ & $19.18 \pm 1.6$ & $22.17 \pm 1.51$ & $23.30 \pm 3.0$ & $35.48 \pm 2.17$ \\
\hline $\mathrm{T7}$ & $4.54 \pm 0.28$ & $13.29 \pm 3.13$ & $37.17 \pm 2.74$ & $17.03 \pm 1.01$ & $21.24 \pm 1.4$ & $22.20 \pm 1.16$ & $23.23 \pm 1.31$ & $38.21 \pm 1.17$ \\
\hline T8 & $4.54 \pm 0.27$ & $13.40 \pm 3.10$ & $36.01 \pm 3.60$ & $17.1 \pm 1.3$ & $19.4 \pm 1.1$ & $23.8 \pm 1.21$ & $25.6 \pm 1.32$ & $38.62 \pm 2.17$ \\
\hline T9 & $5.55 \pm 0.28$ & $4.54 \pm 2.22$ & $41.34 \pm 2.14$ & $18.41 \pm 1.19$ & $19.8 \pm 1.3$ & $24.7 \pm 1.37$ & $26.31 \pm 1.19$ & $39.62 \pm 2.23$ \\
\hline T10 & $5.52 \pm 0.26$ & $3.98 \pm 2.13$ & $41.75 \pm 2.05$ & $18.24 \pm \_1.4$ & $22.0 \pm 1.22$ & $25.8 \pm 1.7$ & $28.12 \pm 1.29$ & $42.10 \pm 2.71$ \\
\hline T11 & $5.63 \pm 0.39$ & $4.68 \pm 2.23$ & $41.47 \pm 2.10$ & $17.9 \pm 1.0$ & $21.32 \pm 1.2$ & $26.12 \pm 1.4$ & $28.12 \pm 1.43$ & $42.76 \pm 2.6$ \\
\hline $\mathrm{T} 12$ & $6.08 \pm 0.60$ & $3.99 \pm 2.16$ & $41.53 \pm 2.07$ & $18.1 \pm 1.2$ & $20.1 \pm 1.15$ & $27.14 \pm 1.34$ & $29.76 \pm 1.43$ & $44.27 \pm 3.21$ \\
\hline
\end{tabular}

\section{DISCUSSION}

The thoracic spine is an important part of the spine. Many pathologies that involve the thoracic spine may require surgical procedures for a better outcome. Increasing use of CT scan has made it possible to determine the morphology of the spine. In our study, we have studied the morphology of the thoracic spine using CT scan.

Transverse pedicle width is crucial for Transpedicular screw fixation. In each level of screw insertion, there should be $1 \mathrm{~mm}$ clearance in width of the pedicle. Our results show that at T1 and T5 levels, $92 \%$ of pedicles were smaller than $5 \mathrm{~mm}$ at $\mathrm{T} 1$ and $84 \%$ of pedicles were smaller than $5 \mathrm{~mm}$ at T5 level. So these pedicles cannot accommodate $4 \mathrm{~mm}$ diameter screw having $1 \mathrm{~mm}$ clearance. Kaur $\mathrm{K}$ et al results on this topic show that at T4 level $76 \%$ of pedicles and at T5 level $62 \%$ of pedicles would not accommodate a screw of $4 \mathrm{~mm}$. At T1 level $2 \%$ of pedicles, T11 level $7 \%$ of pedicles and at T12 level $8 \%$ of pedicles would not accommodate a screw of $4 \mathrm{~mm} .{ }^{10}$ Kretzer et al has done a study on thoracic pedicle morphology in the United States in trauma patients in 2011. He showed that if a pedicle width is smaller and we cannot insert a 
pedicle screw, there are options of laminar hooks and laminar screws and pedicle screw within inout technique. ${ }^{11}$ In this technique, the pedicle screw is inserted from the junction of pedicle and rib head. Another option is to skip the level and apply screws in above and below levels. Our results also show that the pedicle screw should not be inserted in a pedicle with the narrowest width. Because this will jeopardize the spinal cord and nerves. At these levels, other procedures like transpedicular biopsy, vertebroplasty, and decompression can be done to avoid injury.

Our results showed that transverse pedicle angle remained constant from T1 to T4 level with maximum anteromedial angulation at T4 (23.39 \pm $3.15 \mathrm{~mm}$ ) and then gradually when we move caudally from T4 to T12, it decreases to T12 (3.99 $\pm 2.16 \mathrm{~mm}$ ). It means that even at T12 levels in our data, there is no anterolateral angulation. This data will help us in planning the angulation of the pedicle screw. This is important because a medial and lateral breach of the pedicle will jeopardize the adjacent structures. A medial pedicle breach can damage the spinal cord and nerve roots. A lateral pedicle breach can damage the vascular structures in the thorax. Acharaya et al studied the pedicle anatomy and their data showed that at lower thoracic levels, there is anterolateral angulation which is in contrast to our study. ${ }^{13,14}$ Pai et al data showed that there is no anterolateral angulation at lower thoracic levels. ${ }^{12}$ This study results match the results of our study. Kretzer et al data showed right and left side pedicle angulation differences. He found that the left side pedicle needs $1.7^{\circ}$ more angulation as compared to the right side pedicles. The reason is that due to descending aorta, the left side of the pedicles and vertebral body were less developed as compared to the right side. ${ }^{11}$

Depth of anterior vertebral cortex remained constant from T1 level $(29.42 \pm 2.78 \mathrm{~mm})$ to $\mathrm{T} 4$ level $(28.99 \pm 2.66 \mathrm{~mm})$ and gradually increases up to T12 $(41.53 \pm 2.07 \mathrm{~mm})$. This determines the screw length. So T1 to T4 vertebrae level can accommodate a screw length of $25 \mathrm{~mm}$. T5 and T6 levels can accommodate up to $30 \mathrm{~mm}$. T7 to T12 levels can accommodate a screw length of $35-40 \mathrm{~mm}$. Our results match with the study done by Datir et al and Panjabi MM et al. ${ }^{1,9,10,15,16}$ The pedicle screw length in our study is smaller than the Vaccaro $A R$ et al and Zindrick $M R$ et al. ${ }^{17,18}$ Transpedicular screws are biomechanically strong and they incorporate three columns of the spine (anterior, middle, and posterior). Transpedicular screws have a strong cortical purchase of pedicle as compared to the cancellous bone of the vertebral body. The depth of the anterior cortex is important because it determines screw length. If a long screw is applied, it may perforate the anterior vertebral body and damage the intrathoracic structures and main vessels.

Anterior (AP) canal dimensions remain stable between $\mathrm{T} 1$ and $\mathrm{T} 12$ with a minimum at T7 (17.03 $\pm 1.01 \mathrm{~mm})$ and maximum at T2 (21.2 \pm 1.07 $\mathrm{mm}$ ). Interpedicular (IPD) canal dimensions were minimum at T6 $(19.18 \pm 1.6 \mathrm{~mm})$ and maximum at T3 $(23.18 \pm 1.2 \mathrm{~mm})$. The results are shown by Chaynes et al showed an increasing trend in canal size from $\mathrm{T} 1$ to $\mathrm{T} 12$ which do not match our results. ${ }^{19}$ But our results match with the cadaveric studies. ${ }^{1}$

Canal to cord dimensions is important because of the blood supply of the thoracic region. The mid Thoracic region has a critical vascular region at T10 level due to the artery of Adamkiewicz. Mid thoracic region canal dimensions become more important surgically because the less transverse width of pedicles so can put the spinal cord at risk of injury. Thoracic spinal cord dimensions are important anesthetically because of the increasing use of Trans Epidural anesthesia. Trans Epidural anesthesia is given by anesthetists.

Vertebral body height anterior and posterior both gradually increases from T1 down to T12. At all levels, posterior vertebral body height is greater than anterior body height. The reason is 
the physiological kyphosis of the thoracic spine where anterior vertebral height is smaller than posterior vertebral height at all levels. These results match with other cadaveric studies and also with the results of Tan et al. ${ }^{20}$

Vertebral body width increased from $\mathrm{T} 1$ to T12 level. It was minimum at T2 level with a mean of $32.1 \pm 2.41 \mathrm{~mm}$ and maximum at T12 level with a mean of $44.27 \pm 3.21 \mathrm{~mm}$. This is due to the erect posture of humans and weight-bearing of the lower thoracic vertebrae. These results match with the results of Biscevic et al. ${ }^{21}$

\section{CONCLUSION}

Thorough knowledge of the anatomy and radiology of the thoracic spine is essential for both surgeons and anesthetists. Detailed knowledge of anatomy will help in preoperative surgical planning of implant and this will reduce postoperative complications. Our data provide baseline information of the thoracic spine anatomy in our population.

\section{Limitation and Recommendation}

Our study has a few limitations. First is that we have taken axial cuts of CT scan which is twodimensional presentations. The human pedicle has a three-dimensional shape. So a twodimensional presentation is not fully representative of pedicle morphology. Another limitation is that we have used $4 \mathrm{~mm}$ slice thickness of CT scan. We may miss valuable information between slices. Acharaya et $\mathrm{al}^{13}$ has used $3 \mathrm{~mm}$ slice thickness of CT scan. Datir et al ${ }^{15}$ has used $5 \mathrm{~mm}$, slice thickness. When we compare the data of these studies, the results are not significant.

\section{REFERENCES}

1. Singh R, Srivastva SK, Prasath CS, Rohilla RK, Siwach R, Magu NK. Morphometric measurements of cadaveric thoracic spine in Indian population and its clinical applications. Asian Spine J. 2011; 5 (1): 20-34.

2. BeyerB, Biteau D, Snoeck O, Dugailly PM, Bastir $M$, Feipel V. Morphometric analysis of the costal facet of the thoracic vertebrae. Anat Sci Int. 2020; 95 (4): 478-488.

3. Drake RL, ed. In: Textbook of Gray's Anatomy for Students1st ed. Philadelphia: Churchill Livingstone Publications, 2005: PP. 33-63.

4. Romanes GJ, ed. Cunninghams Manual of Practical Anatomy. New York: Oxford University Press. 1996; 15th ed., Vol. II: PP. 3-82.

5. Bianco RJ, Arnoux PJ, Mac Thiong JM, Aubin CE. Thoracic pedicle screw fixation under axial and perpendicular loadings: A comprehensive numerical analysis. Clin Biomech (Bristol, Avon). 2019; 68: 190-196.

6. Elder $\mathrm{BD}$, Lo SF, Holmes $\mathrm{C}$, Goodwin $\mathrm{CR}$, Kosztowski TA, Lina IA, et al. The biomechanics of pedicle screw augmentation with cement. Spine J. 2015; 15 (6): 1432-45.

7. Kayacı S, Cakir T, Dolgun M, Cakir E, Bozok Ş et al. Aortic Injury by Thoracic Pedicle Screw. When Is Aortic Repair Required? Literature Review and Three New Cases. World Neurosurg. 2019; 128: 216-224.

8. Smith ZA, Sugimoto K, Lawton CD, Fessler RG. Incidence of lumbar spine pedicle breach after percutaneous screw fixation: a radiographic evaluation of 601 screws in 151 patients. J Spinal Disord Tech. 2014; 27 (7): 358-63.

9. Quiroga O, Matozzi F, Beranger M, Nazarian S, GambarelliJ et al. Normal CT anatomy of the spine. Anatomo-radiological correlations. Neuroradiology. 1982; 24 (1): 1-6.

10. Kaur K, Singh R, Prasath V, Magu S, Tanwar M. Computed tomographic-based morphometric study of thoracic spine and its relevance to anaesthetic and spinal surgical procedures. J Clin Orthop Trauma. 2016; 7 (2): 101-8.

11. Kretzer RM, Chaput C, Sciubba DM, et al. A computed tomography-based morphometric study of thoracic pedicle anatomy in a random United States trauma population. J Neurosurg Spine, 2011; 14: 235-24.

12. Pai BS, Nirmala GS, Muralimohan S, Varsha SM. Morphometric analysis of the thoracic pedicle: ananatomico-radiological study. Neurol India, 
2010; 58 (2): 122-136.

13. Acharya $S$, Dorje T, Srivastva A. Lower dorsal and lumbar pedicle morphometry in Indian population. A study of four hundred fifty vertebrae. Spine, 2010; 35: E378-E384.

14. Chadha M, Balain B, Maini L .Pedicle morphology of the lower thoracic, lumbar, and S1 vertebrae: an Indian perspective. Spine (Phila Pa 1976), 2003; 28 (8): 744-9.

15. Datir SP, Mitra SR. Morphometric study of the thoracic vertebral pedicle in an Indian population. Spine (Phila Pa 1976), 2004; 29 (11): 1174-81.

16. Panjabi MM, O'Holleran JD, Crisco 3rd JJ. Complexity of the thoracic spine pedicle anatomy. Eur Spine J. 1997; 6 (1): 19-24.

17. Vaccaro AR, Rizzolo $S$, Allardyce $T J$, et al. Placement of pedicle screws in the thoracic spine. Part I: Morphometric analysis of the thoracic vertebrae. J Bone Joint Surg Am. 1995; 77: 11931199.

18. Zindrick MR, Wiltse LL, Doornik A, et al. Analysis of the morphometric characteristics of the thoracic and lumbar pedicles. Spine, 1987; 12: 160-166.

19. Chaynes P, Sol JC, Vaysse P, Becue J, Lagarrigue J. Vertebral pedicle anatomy in relation to pedicle screw fixation: a cadaver study. Surg Radiol Anat. 2001; 23: 85-90.

20. Tan SH, Teo EC, Chua HC. Quantitative threedimensional anatomy of cervical, thoracic and lumbar vertebrae of Chinese Singaporeans. Eur Spine J. 2004; 13: 137-146.

21. Biscevic M, Biscevic S, Ljuca $F$, et al. Clinical and radiological morphometry of posterior parts of thoracic and lumbalvertebras. Coll Antropol. 2012; 36 (4): 1313-1317.

\section{Additional Information}

Disclosures: Authors report no conflict of interest.

Ethical Review Board Approval: The study was conformed to the ethical review board requirements.

Human Subjects: Consent was obtained by all patients/participants in this study.

\section{Conflicts of Interest:}

In compliance with the ICMJE uniform disclosure form, all authors declare the following:

Financial Relationships: All authors have declared that they have no financial relationships at present or within the previous three years with any organizations that might have an interest in the submitted work.

Other Relationships: All authors have declared that there are no other relationships or activities that could appear to have influenced the submitted work.

\section{AUTHORS CONTRIBUTIONS}

\begin{tabular}{|l|l|l|}
\hline Sr.\# & Author's Full Name & Intellectual Contribution to Paper in Terms of: \\
\hline 1. & Waqas Noor Chughtai & 1. $\quad$ Study design and methodology. \\
\hline 2. & Muhammad Adeel Razzaque & 2. Paper writing, referencing, and data calculations. \\
\hline 3. & Tanveer Ahmad & 3. Data collection and calculations. \\
\hline 4. & Sumera Nighat & 4. Analysis of data and interpretation of results etc. \\
\hline 5. & Rahila Tahir & 5. Literature review and manuscript writing. \\
\hline 6. & Bashir Ahmad & 6. Analysis of data and quality insurer. \\
\hline
\end{tabular}

